\title{
COMO PERCEBI A INEFICIENCIA DO ENSINO DE ENFERMAGEM PEDIÁTRICA NO ASPECTO REFERENTE A ASSISTENCIA AOS PAIS.
}

\author{
Esther Moraes * \\ Maria do Amparo Oliveira de Paula -
}

MORAES, E. \& PAULA, M. do A.O.de. Como percebi a ineficiência do ensino de Enfermagem Pediátrica no aspecto referente à assistência aos pais. Rev. Esc. Enf. USP, São Paulo, 14 (3): 243-256, 1980.

Focalizam-se e analisam-se posstveis causas de resisténcia das alunas na realizaçđo de certas tarefas na disctplina Enfermagem Pediatrica.

\section{INTRODUÇÃO}

Preparava-me para analisar o resultado da minha orientação a um grupo de alunos, que cursou a disciplina Enfermagem Pediátrica em 1976, imaginando que poderia divulgar os resultados da utilização de determinada metodologia na comunicaç̃o com pais visitantes de crianças hospitalizadas, quando, de repente, deparei com a autoavaliação de Maria do Amparo, aluna formada em 1977, colaboradora deste artigo, os seguintes comentários sobre sua experiência de campo:

“Não posso dizer que esta foi a melhor técnica a ser usada no caso. Nem que me saí maravilhosamente bem ..."

Depois, no final da avaliação;

"Também não foi muito programada a minha assistência. Foi algo mais sentido, percebido de suas necessidades (da mãe) num momento".

Embora esteja patente o resultado positivo da assistência, no relato de Maria do Amparo, apresentado no anexo 1, ela não está satisfeita; demonstra insegurança em relação ao modo pelo qual assistiu a mãe.

$\mathrm{Na}$ primeira vez que analisei o trabalho, achei-o excelente, Maria do Amparo recebera nota dez e eu entendi que a experiência tinha, provavelmente, tido grande significado para ela.

No momento, três anos depois, revendo a avaliação, constato a ineficiência daquele meu modo de conduzir o ensino. Embora a minha preocupação tivesse sido proporciona o maior número possivel de experiências significantes, náo o conseguira.

Docente da disciplina Enfermagem Pedítrica da EEUSP.

- Estudante de enfermagem que cursou a disciplina Enfermagem Pediátrica da EEUSP em 1976. 
Observo que so $10 \%$ dos alunos, se tanto, têm tido experiências com significado para eles; $90 \%$ mantêm-se pouco motivados, permanecem afastados do entusiasmo que sinto em relação aos resultados de aplicação de toda a ciência e arte relacionadas à enfermagem pediátrica. Tudo isto, naturalmente, me traz um sentimento desagradável e a consciência da limitaçáo e da ineficiência do ensino.

Há três anos, na disciplina Enfermagem Pediátrica, o preparo do aluno para dar assistência aos pais tem sido um desafio. Turmas seguidas tếm oferecido grande resistência a esta tarefa. A argumentação dos alunos tem sido variada mas persistente. Houve um grupo que se recusou a fazer esta tarefa. Na época deram-me explicaçóes que não fui capaz de entender; disseram-me que preferiam não fazer esse trabalho porque não queriam me enganar, levando-me a supor que tinham dado essa assistência; não queriam ser desonestos.

Haveria alguma razão especial para a resistência dos alunos nesta tarefa? pensei; imagino que sim.

Vou focalizar para os colegas docentes o possivel significado desta resistência. $\mathrm{Na}$ verdade, compreendo, agora, que era uma resistência relacionada a todas as tarefas que as professoras propunham; manifestou-se de forma aguda na assistência aos pais, por razóes que passo a explicar.

O tema assistência aos pais de crianças doentes ou convalescentes, na disciplina Enfermagem Pediátrica, é aquele que considero fundamental para a contribuição dos enfermeiros na melhoria da situação de saúde da criança brasileira.

A fim de aperfeiçoar a orientação dada aos alunos, tenho me mantido atenta às experiências dos alunos nesse campo em diferentes circunstâncias; e assim tenho adquirido certa convicção pessoal sobre o modo de ver e tratar os pais. Acredito que:

- a atitude da enfermeira, perante as pessoas, vai implicar no alcance da intervenção de enfermagem; dependendo da atitude de confiar ou não nas pessoas, que elas são capazes de resolver seus problemas, os pais podem se desenvolver ou não no atendimento de seus filhos;

- a capacidade da enfermeira de controlar suas emoçס̋es quando observa, direta ou indiretamente, o atendimento dado pelos pais as crianças é um aspecto a ser considerado; sem um estudo criterioso da situação, a enfermeira poderá interpretar mal e apressadamente a atitude dos pais em relação à criança;

- considerando que os pais são pessoas capazes de pensar, sentir e agir em benefício de seus filhos o papel da enfermeira concentra-se mais em reforçar essa capacidade em solucionar os problemas da criança; este papel é significante porque vai tomá-los mais humanos; vai capacitá-los a melhor perceber as reaçóes dos filhos e a selecionar os cuidados que atendem ds necessidades das crianças;

- o interesse e o amor dos pais sáo recursos naturais em favor das crianças; em qualquer iniciativa de assistência, se estes recursos não forem sondados e mobilizados, haverá, provavelmente, limitação dessa assistência;

- as enfermeiras e os estudantes de enfermagem tểm dificuldade em ajudar os pais. Suponho que as causas sejam as seguintes: não selecionarem uma teoria, dentre os ramos de Psicologia para explicar o comportamento dos pais; não utilizarem um método ao se comunicarem com eles; não apresentarem uma atitude adequada e náo demonstrarem conhecimento a respeito das causas que deteminam o comportamento dos pais quando seus filhos estão hospitalizados.

A conseqüência destas minhas convicçóes é que eu tenho exigido muito de meus alunos porque sei o que se pode fazer. Sei que as perspectivas de saúde de uma 
criança podem ser mudadas se, em todas as oportunidades de contato com os pais, nos aproximarmos deles com interesse em estudar e compreender a situação que estão vivendo e utilizarmos um pouco das técnicas de comunicação não diretiva.

Alguns alunos já me disseram que eu não podia ter exigido tanto deles, sobretudo emocionalmente.

Por outro lado, revendo os relatos dos alunos, compreendo as dificuldades naturais que o principiante deve sentir ao entrevistar pessoas altamente ansiosas, que solicitam muito apoio e esclarecimentos para problemas muito delicados.

Imagino, agora, que é muito difícil aos alunos controlarem-se emocionalmente e não se contagiarem com a ansiedade dos pais visitantes, que não estáo recebendo orientaçáo e apoio do pessoal hospitalar responsável pela assistência a seus filhos. Tenho observado que os alunos sáo, na maioria das vezes, as primeiras pessoas a se colocarem à disposição de pais tremendamente aflitos, que os crivam de perguntas e expressam forte carga emocional à primeira pessoa que se prontifica a ouvi-los.

As outras razōes que identifico, da resistência dos alunos prendem-se à qualidade da orientação dada por mim e ao fato de a atribuição de nota dada no relato da experiência ficar submetida somente ao critério do professor. aos pais?

Como estava eu orientando e avaliando a experiência dos alunos na assistência

Basicamente oferecia informaçøes que lhes possibilitasse;

- observar, explicar e classificar as reaçðes dos pais de crianças sadias e doentes;

- iniciar e manter relacionamento significante com os pais; $e$

- utilizar determinada metodologia a fim de tranqüilizar, aconselhar e deles obter informaçőes úteis.

No anexo 2 está apresentada a orientação que dávamos aos alunos.

O problemas que vejo nesta orientação é a sua qualidade; esta sugerida, de maneira muito enfática, a maneira de atuar numa entrevista, à não diretiva, e fazia recomendaçōes a respeito de técnicas de comunicação. Este direcionamento, talvez tirasse dos alunos a possibilidade de examinarem outras altemativas para abordar os pais.

Finalmente, o fato da avaliação do relatório da assistência aos pais depender, para efeito de nota, das expectativas da professora, provavelmente criava um clima avesso ao comportamento espontâneo do aluno.

Todas estas circunstâncias podem ter impedido a existência de um ambiente favorâvel à aprendizagem e ter sido a causa da resistência dos alunos à tarefa de orientar os pais.

Como vejo a experiência de Maria do Amparo?

No passado, o seu trabalho foi, entre todos os relatórios dos alunos que atenderam à minha orientação, o que mais me agradou. Ele representava aquilo que eu sentia, com tanta acuidade, como problema da Enfermagem Pediátrica - a ansiedade: dos pais; era o relatório que mais representava os efeitos de uma entrevista não dire- 
tiva, método que, de modo geral, eu considero ser um dos mais práticos para assistir as pessoas; e também, porque o relato é representativo do relacionamento enfermeiramáe, com efeito terapêutico, qualidade única de relacionamento, quando penso em boa enfermagem.

Maria do Amparo atendeu a todos os objetivos propostos na orientação; observa, descreve e compreende o comportamento da mae; controla-se em suas perguntas para não aborrecer, ameaçar ou gastar muito tempo da mâe (Esta é a recomendação de $\mathrm{KORSCH}^{1}$ ); açбes, para tranqüilizar a mãe, são demonstradas em muitos cuidados de enfermagem. Em primeiro lugar, consegue explorar suas fontes de ansiedade; explica procedimentos cirúrgicos; coloca-se à disposição da mãe para esta fazer perguntas; aceita os sentimentos da máe ouvindo-a falar de seus medos, relativos à extrofia vesical, à definição do sexo da filha e à aparência dos genitais da menina; estimula maior aproximação física entre a mãe e filha e explica as razóes do comportamento da menina (choro, balanceio e onicofagia). Na solução dos problemas da máe, Maria do Amparo incentiva-a a buscar informaçð̌es com o médico e a trocar experiências com outras máes de crianças com extrofia vesical.

Eu me apeguei a este relato e concluí; é assim que as mães devem e precisam ser assistidas. A minha orientação deu resultado !

Três anos depois, entretanto, relendo a auto-avaliação de Maria do Amparo, vejo que o resultado para ela não foi bom. Sua dúvida quanto à eficiência da utilização das técnicas recomendadas é um ponto muito negativo; pior ainda é o conflito demonstrado quanto à ação de programar. Seguindo a orientação dada, só são programados antecipadamente a atitude e o modo de abordar os pais, mesmo porque a programação é dinâmica e contínua. Enfím, Maria do Amparo saiu da experiência desorientada e com dúvidas.

Dentro do método tradicional, no qual a participação do aluno na organização das atividades é praticamente nula, nada tem significado para ele.

O que de significativo se aprende dentro do sistema tradicional? Eu nada aprendi.

Lendo "Liberdade para aprender", de Carl Rogers, compreendendo a força vitalizante do clima terapêutico para a criança, como é a situação de brincadeira na presença de uma pessoa amiga, e, questionando-me quanto ao como e ao quando eu aprendi enfermagem, compreendi que o método que eu estava utilizando para ensinar os alunos era anti-natural e mesmo perigoso do ponto de vista da formação profissional.

Aprendi enfermagem quando tive liberdade de atender as minhas necessidades, dúvidas e curiosidades. Quando eu me dispus a entender um fenômeno, longe das ameaças e expectativas padronizadas, organizei-me para ver, compreender e atuar junto a crianças e familiares de forma integrada - pensamentos, sentimentos e açoes. Das situaçőes em que fui estudar aquilo que eu queria, sempre ficou algo de permanente; ganhei auto-confiança; surgiram valores originados de minha experiência e năo de experiências das outras pessoas. Senti-me integrada.

Finalmente tomei consciência de que as experiências significantes têm que nascer da motivação, das dúvidas e de curiosidade de cada um. Toda pessoa é capaz de analisar fenômenos, sem ser conduzida, inclusive identificar os aspectos negativos de sua experiência imediata. Quando em liberdade para aprender descobre-se uma força nunca vista. Em lugar de qualquer sinal de resistência aparece naturalmente, autodisciplina. Nestas condiçס̃es a pessoa fica envolvida em seu todo. $\mathrm{O}$ resul- 
tado é uma organização interna nova para enfrentar as situaçб̌es da vida. A cada experiência significante estrutura-se uma pessoa nova.

Concordo plenamente com ROGERS 2, quando ele afirma que ..." qualquer coisa que eu possa ensinar a outro é relativamente irrelevante e tem pouca ou insignificante influência sobre o comportamento".

Por que não vou dar condiçð̋es aos meus alunos de viverem melhor como pessoas?

(Em outros artigos pretendo expôr como a disciplina tomou nova direção e como a assistência aos pais passou a ser um tema de interesse e de realização para os alunos).

MORAES, E. \& PAULA, M. do A.O. de. How perceived inefficiency in the teaching of Pediatric Nursing, in relation to the assistance given to parents. Rev. Esc. Enf. USP, São Paulo, 14 (3): 243-256, 1980.

The possible causes for the student's resistance in regard to the realization of certain tasks in the discipline of Pediatric Nursing are focalized and analysed.

\section{REFERENCIAS BIBLIOGRÁFICAS}

1. KORSH, B.M. Practical techniques of observing, interviewing and advising in practice as demonstrated in an attitude study project. Pediatrics, Springfield, 18:467-90, 1966.

2. ROGERS, C. Liberdade para aprender. Belo Horizonte, Inter-livros, 1972. p. 150-1. 


\section{ANEXO 1 \\ RELATO DA EXPERIENCIA DA ALUNA NA ASSISTENCIA \\ À MÃE VISTT ANTE.}

\section{Aluna: Maria do Amparo Oliveira de Paula.}

G. é uma garotinha de cabelos louros, encaracolados e finos e olhos castanhos. Tem dois anos de idade. Foi internada na clínica urológica pela terceira vez. Sua extrofia vesical foi reparada. Na primeira etapa foi feita ureterosigmoidostomia; na segunda, tubulização do trígono e plástica de parede por rotação de retalho. Desta vez a cirurgia foi anastomose vesicosigmoideana.

0 que me chamou a atenção em $\mathrm{G}$. foi o seu isolamento, sua carência de afeto. Ela apresentava balanceio de cabeça e onicofagia. Só falava uma e outra palavra e chorava quando ficava sozinha.

Assim, resolvi falar com a mãe para saber como era o comportamento desta criança em casa.

A cena que presenciei foi a seguinte:

G. estava deitada no berço e a mãe, ao lado, apoiando-se na grade, segurava-lhe a mão e acariciava-lhe a testa; a criança, ainda assim, balançava de um lado para outro.

Aproximei-me pelo outro lado do berço. Sorri para a mãe e nossa conversa teve in ício. Dirigindo-me a G., comentei:

$A^{*}$ - Nem quando a mamãe está aqui você pára?

$\mathbf{M}^{*}$ - Ela é assim mesmo. Desde pequenininha ela faz isso.

A - E rói unhas também?

M - Não. Estou percebendo que ela está com a ponta dos dedinhos vermelhos. A máe olha demoradamente para $\mathbf{G}$.

M - Será que ela está nervosa?

A - Ela está sentindo falta da senhora, falta de carinho.

Dirigi-me a G.

A - Mesmo uma dúzia de "tias" não valem uma mãe, não é G.?

M - Ela não está acostumada a ficar sozinha; eu cuido dela o dia inteiro.

A - A senhora náo trabalha fora?

M - Não. O que meu marido ganha dá para a gente viver bem. Eu só não venho todo dia, porque é muito longe. Moro em Santo Amaro. 0 menino năo pode ficar sozinho, ele só tem cinco anos.

* Aluna

* Mãe 
Fez uma pausa e continuou:

M - A "G." gosta muito dele.

Fiquei olhando para a garota, sem saber o que dizer, e, olhando para G. falei:

A - Como ela é em casa?

M - E muito espertinha. Corre para todo lado. Brinca muito. Fala tudo. Come tudo que se dá. Ela é muito boazinha.

A - Ela sabe pedir para fazer as necessidades?

M - Ela pede para fazer "cocô". Mas "xixi", a senhora sabe, por causa da bexiguinha dela ser do jeito que é, não pode pedir. Eu é que tenho que ver quando ela está molhada.

Fez uma pausa. Olhou para a criança e acariciou-lhe a mãozinha. Depois continuou, falando baixo e devagar.

M - Quando ela nasceu, eu fiquei apavorada. Não sabia nem como tocar nela. Ela chorava muito. Acho que aquilo doía muito. $\mathrm{O}$ médico me explicou o que era aquilo e me ensinou a cuidar dela. Eu fiz tudo direitinho: dava banho, passava pomada; comprei muitas fraldas bem macias para ela; ño deixava ela molhada nem um pouquinho. Tanto que ela não pegou nenhuma inflamação.

Olhou-me, como pedindo aprovação. Sorri e balancei afirmativamente a cabeça.

M - Eu tinha muito medo disso, sabe? Eu nunca pensei que ela era a única que tinha esse defeito. Nunca imaginei que uma criança pudesse nascer assim. Ninguém por aí, sabe. Para trocar fraldas é uma tristeza. Quando ela foi crescendo então... começou a andar, não parava quieta. Eu tinha medo que aquilo inflamasse ...

Fez uma pausa e suspirou.

M - Ainda bem que isso passou. Agora, ela não dá mais tanto trabalho.

Olhou em volta, sorriu para outra máe; percebi que gostaria de ir ter com ela.

A - Se a senhora quiser ficar mais perto de G., pode abaixar a grade do berço, pegá-la no colo, trocar a fralda, se estiver molhada. Se precisar ou quiser fazer alguma pergunta, eu estou por aqui mesmo.

Ela sorriu timidamente e agradeceu. Depois pegou a criança no colo e foi conversar com as outras senhoras.

A primeira impressáo que tive da mãe de G. foi muito boa. Embora um pouco timidamente, ela me contara algo do que ia por dentro. Fiquei contente por ela ter podido desabafar um pouco. E uma máe bastante jovem, cujo segundo filho apresentou um problema inesperado.

Ouvi-a conversar com outras máes de crianças com extrofia vesical. Queria saber como estava a criança, que operaçōes já tinha feito,o que a mãe estava sentindo.

Depois voltou-se para mim e perguntou:

M - Será que quando eu voltar ela já foi operada?

A - Não sei, os médicos ainda não marcaram a data da cirurgia.

M - Será que desta vez vai demorar para sarar?

A - Isso não se pode prever. Vai depender das condiçбes de G. depois da operação. O médico está aí, quer que eu pergunte à ele? 
M - Pode deixar que eu pergunto. Preciso mesmo saber o que vão fazer.

$\mathrm{E}$ foi falar com o médico, deixando G. no berço.

Olhei-a de longe e tive a impressão de que ela não conseguia se expressar bem, ou então não estava entendendo a explicação.

Voltou para junto de G. e disse:

M - A mamãe já vai embora, filhinha. Amanhã a mamãe volta.

Dirigiu-se a mim e comentou:

M - Já sei que são vocês que ficam aqui de manhã. A senhora está cuidando dela, não é?

Fiz que sim, com a cabeça.

M - Cuide bem dela para mim.

E, já saindo, disse:

M - Fica com a titia, G.

A garota chorou no meu colo, estendendo os braços em direção à porta. Aos poucos, foi se acalmando e adormeceu. Só então fui embora.

$\mathrm{O}$ que entendi dessa senhora é que ela estava bastante ansiosa. $\mathrm{E}$, desde que a garota nascera, tinha sido assim.

Ainda que gostasse muito da criança e cuidasse muito bem dela, essa ansiedade, esse medo de machucar estavam impressos em seus gestos e em sua face. E por isso o balanceio de G. Ela sentia falta de calor humano, de gente que a tratasse sem medo, como uma criança qualquer. Pensei em dizer isso d̀ mãe numa próxima visita.

\section{Segunda entrevista.}

Era uma quinta-feira, G. tinha sido operada na segunda. Estava ainda com saquinho coletor na sigmoidostomia e uma sonda vesical aberta. $\mathrm{O}$ "soro" já havia sido retirado.

Quando cheguei, a criança estava em decúbito dorsal, balançando a cabeça desesperadamente. A mãe olhava-a como se não soubesse o que fazer. Aproximeime devagar; ela sorriu sem jeito, tentou arrumar a blusinha da garota.

G. começou a chorar alto e forte.

A máe me olhou perplexa.

A - Ela está com medo que a gente toque no curativo. Tem medo da dor.

M - Deve doer muito.

Olha para a menina e diz:- "A mamãe não vai te machucar".

A - A senhora pode pegá-la no colo. Ela não está mais com "soro".

M - Ainda bem que eu não vim antes. Fico desesperada, quando vejo ela com todos esses fios.

Entendi que ela tentava desculpar-se.

M - Eu não sabia que ela já tinha sido operada.

Fez uma pausa e me olhou.

M - Como é que eu posso pegá-la?

Desci a grade do berço, desatei o coletor da cama e voltei-me para ela. 
A - Ela vai gostar de ficar no seu colo. Pode pegá-la, não tenha medo. A sonda não sai facilmente.

Ela tomou a criança nos braços, a princípio, com muito cuidado; mas depois, ao perceber que G. parara de chorar, abraçou-a sorrindo e murmurando palavras carinhosas.

Voltando-se para mim, disse:

M - Não está saindo nada por essa sonda?

A - É verdade. Ela está aí para manter o canalzinho aberto. Mas por enquanto o "xixi" sai por aquela outra abertura. (Apontei a sigmoidostomia).

M - Mas, então, o que foi que eles fizeram?

A - Eles pegaram aquele pedaço de intestino que estava servindo de bexiga e ligaram na bexiga de verdade, para este ficar maior.

M - Mas, até quando vai ficar assim?

A - Acho que só mais uma semana. Assim que cicatrizar o corte da operação os médicos fecham essa abertura e o "xixi" sai por onde deve sair.

M - E por fora, vai ficar assim? Eles não fazem um plástica, para ela ficar igual a todo mundo?

A - Por enquanto, o mais importante é saber se ela vai poder fazer "xixi" como todo mundo.

Arrependi-me de ter dito isso a ela. Deve ter parecido uma censura, embora eu não tivesse essa intenção.

A - Há médicos que fazem esse tipo de plástica. Não sei se é o caso dela. Mas, mesmo assim, quando ela crescer e nascerem os pelos, não vai dar para perceber.

$M$ - Eu não queria que ela crescesse assim.

A - Posso perguntar ao médico se ele pode indicar alguma coisa nesse sentido.

Ela pareceu refletir um pouco, depois disse:

M - É bobagem minha, você tem razão. $O$ importante é que ela faça "xixi" direitinho.

Ela silenciou e resolvi deixá-la só para que conversasse com as outras máes.

Percebi que ela se sentia muito melhor quando conversava com as mães de crianças que também tinham extrofia vesical. Só assim, ela se convencia de que a sua filha, não era a única com esse "defeito"; que pelo contrário, ele é bastante comum. Como ela nunca tinha ouvido falar nisso, ficava pensando que era a única mãe no mundo a ter um filho nessas condiçбes.

Quando a máe deixou a criança no berço, ajudei-a e tentei consolar G., enquanto a máe saía.

Nesse dia, ao sair do hospital, pensei em falar com o médico sobre uma possível plástica, mas já sabia que ele náo faria esse tipo de cirurgia, pois, nessa clínica, só cuidam da parte urológica; mas talvez pudesse encaminhar G. para um outro médico. De qualquer forma precisava diminuir a ansiedade da mãe quanto a isso.

\section{Terceira entrevista:}

G. já estava bem. Tinha passado a fase em que ela gritava desesperada, só de pensar que alguém ia tocar no curativo. Não roía as unhas. A nossa assistência, pela manhã e uma certa mudança de atitude da mãe, à tarde, estavam surtindo efeito. Além do 
mais, a sigmoidostomia tinha sido suturada e a sonda vesical retirada. Ela já não chorava quando sozinha. Falava bastante. Tinhamos conseguido uma boa evolução no seu comportamento.

Quando entrei, G. estava sentada na cama, comendo chocolate, com um boneca no colo. Ninava a boneca no mesmo ritmo do seu balanceio. A mãe estava ao lado, tirando-lhe os cabelos dos olhos e sorrindo.

Ao me avistar, foi dizendo:

M - Viu como ela está boazinha? O médico disse que daqui a dois dias ela já pode ir embora.

A - É verdade. Se tudo correr bem, ela poderá ir embora. Antes é preciso saber se ela está conseguindo fazer o "xixi".

M - Então, não é certeza?

A - É quase certo. Ainda assim, é preciso que a senhora a observe bem e a traga ao consultório no dia em que o médico mandar.

A senhora deve observar se ela consegue segurar o "xixi" ou se a fralda fica constantemente molhada.

G. começou a pular no berço. Apertou a boneca fazendo um grande barulho. A mãe tentou desculpá-la.

M - Que farra é essa G.? Você está num hospital!

A - Não se preocupe. É bom que ela brinque, como uma criança normal. Ela fez todas as operaçס̄es e está tudo bem. Não é G.?

M - Eu falei com o médico sobre a plástica. Ele disse que só pode fazê-la, quando ela crescer.

Balancei afirmativamente a cabeça e não soube o que dizer. Ela parecia querer dizer algo e não sabia como começar.

Olhei para a menina.

A - G. está uma menina muito bonita.

M - Que bom que ela é bonita.

Hesitou, depois continuou:

M - Eu nunca falei para as vizinhas o que ela tinha. Ninguém nunca tinha ouvido falar nisso. Eu não queria que, quando ela crescesse, eles dissessem que ela era "duvidosa". Que não tinham certeza de que era menina mesmo. Não é bom que isso se espalhe. Não quero que fiquem falando dela.

Olhei-a interrogativamente.

Ela explicou:

M - Quando ela nasceu, a gente não sabia que tinha uma vaginazinha debaixo daquilo isto é, da bexiga. Não dava para ver e eu tinha medo de mexer para olhar. Você sabe, num lugar onde todo mundo se conhece, se eles ficassem sabendo que ... Se o médico não tivesse dito eu não saberia se era menino ou menina. Ia ser uma falação. G. não ia ter sossego nem depois de grande.

Foi aí que percebi exatamente o porquê da sua grande preocupação pela plástica. Ela estava pensando nos vizinhos. E não só neles. 
A - Mas, agora está tudo certo.

M - Graças a Deus ! Mas, mesmo assim, é melhor não falar nada. Eles não iriam entender. Ainda bem que, agora, qualquer um pode ver que ela é menina, sem precisar tirar a fralda.

Eu fiquei quieta. Não sabia o que dizer.

$M$ - Eu nunca tinha dito isso para ninguém.

E olhando para as outras mæes, comentou:

$M$ - Elas parecem não ter esse problema.

E olhando para G., disse:

M - A mamãe vai descer para ficar com o seu irmãozinho, e o papai poder subir.

Beijou-a e saiu.

A garota ficou em pé no berço, sacudindo-o todo.

Quando o pai entrou, ela aumentou o barulho, pisando na boneca para que ela emitisse um assobio.

Ele aproximou-se do berço, mas não falou com a garota.

Pareceu intimidado com minha presença.

Sorri, cumprimentei-o e retirei-me.

Ele pegou-a no colo e levou-a para o terraço.

Não me pareceu ansioso, assim também como a mãe, nessa última entrevista.

Deixei G. no colo do pai e fui embora.

Não encontrei mais G. nem seus pais. De fato ela teve alta há dois dias e deveria voltar ao ambulatório para ser verificado se estava havendo controle esfincteriano.

Avaliação:

Não posso dizer que esta foi a melhor técnica a ser usada no caso. Nem que me saí maravilhosamente bem. Tive as minhas falhas, é claro. Mas creio que houve, também, muitos pontos positivos.

Consegui que a mãe mudasse um pouco sua forma de tratar a filha. De agora em diante, ela não tratará a filha como uma raridade de museu.

Estimulei o contato físico entre a mãe e filha.

Não a crivei de perguntas, mas permiti que ela fizesse perguntas e que conversasse com as outras mães.

Quanto d plástica, tudo que podia ter feito era ouví-la.

Tive oportunidade, também, de fazer algum preparo para a alta - a observação para saber do controle do esfíncter uretral. G.

Sei que devo muito de sua confiança em mim, pelo fato de eu estar cuidando de

Também, não foi muito programada a minha assistência. Foi algo mais sentido, percebido, de suas necessidades, num momento. 


\section{ANEXO 2 \\ À GUISA DA ORIENTAÇÃO *}

Inicialmente, orientávamos os alunos para a turefa de avaliar a capacidade das pessoas em compreender e atender a criança "sadia", em seus aspectos de crescimento e desenvolvimento. Sobre o comportamento dos pais, apresentávamos aos alunos: os tipos de pais segundo JERSILD ${ }^{9}$; as qualidades do comportamento materno segundo RHEINGOLD 15; as categorias do comportamento materno, quando há ou não ajustamento ao papel de mãe, segundo HARRISON ${ }^{7}$; e as sugestðes de $\operatorname{KORSCH}^{10}$ para observar as mães durante a consulta médica.

A finalidade desta orientação era levar o aluno a perceber e aceitar as mães altamente, mediamente e pouco maternais.

No tratamento dos distúrbios de relacionamento entre mãe e filho, utilizavámos os padróes de comportamento materno de PORTER 14, que podem orientar os alunos na identificação destes casos. Para ilustrar as síndromas de crianças com crescimento muito prejudicado e de crianças espancadas, utilizamos as referências de HARRISON $^{7}$, MARLOW ${ }^{13}$, FRIEDMAN et alii ${ }^{6}$, ECKELLS $^{4}$ e COATES $^{3}$, que também orientam quanto à intervenção de enfermagem junto a estes pais.

A fim de orientar os alunos na tarefa de estabelecer relacionamento significante com os pais de crianças hospitalizadas, discutíamos com eles os fatores que explicam as reaçסes dos pais vivendo determinadas situaçð̄es no hospital. Assim, com base em ISSNER 8 , analizávamos as conseqüências do impacto da doença e da separação na família. Para justificar as reaçðes dos pais de crianças internadas, utilizávamos os trabalhos de SCOFIELD ${ }^{17}$ e de FREIBERG ${ }^{5}$ que caracterizam o comportamento predominante dos pais, as situaçбes que mais os amedrontam, as preocupaçðes principais e as razðes de suas ansiedades.

Ao tratar da ansiedade dos pais, discutíamos as experiências de MAHAFFY 11,12 , BRIGHT $^{1,2}$ e ROY ${ }^{16}$, que oferecem elementos para os alunos poderem aceitar os pais ansiosos e aprender a tranquilizá-los, utilizando medidas simples e eficientes como por exemplo: prestando atençáo ao foco de atenção dos pais, informando-os sobre o estado de saúde do fillho e facilitando o envolvimento dos pais no cuidado da criança hospitalizada, sob orientação do enfermeiro.

A finalidade desta exposição era tomar os alunos conscientes do papel do enfermeiro, isto é, de oferecer apoio e orientaçð̌es para eles poderem retomar adequadamente o seu papel de pai ou mãe, dentro da unidade de internação, estivesse o filho gravemente doente ou convalescente. A nossa ênfase era demonstrar, na prática, a importância de aceitar a participação dos pais na recuperação da criança internada.

- $\quad$ Roteiro da aula até 1978. 
Naturalmente, quando os alunos assistiam pais em condições especiais como em cirurgia, morte da criança, oferecíamos apoio diariamente aos alunos e eles consultavam a bibliografia específica, que era possível encontrar. Esta também era a conduta, quando eles precisavam ajudar os pais de crianças acidentadas, com deficiência físicas e mentais ou portadoras de anomalias congênitas.

Além das informaçōes acima citadas sobre referências utilizadas pelos alunos para se situarem à compreensão das reaçס̄es dos pais que visitam ou acompanham os filhos internados, dávamos-lhes oportunidade de entrevistar, duas, três e mais vezes consecutivas, pais de crianças que estavam internadas e recebiam tratamento clínico, cirúrgico ou de emergência. Nosso objetivo, nesta prática de campo, era levar os alunos a estabelecerem uma relação significante com os pais, utilizando algumas técnicas de comunicação.

\section{SUGESTŐES PARA ENTREVISTAR OS PAIS VISITANTES}

Sugeríamos que fizessem a tarefa aos pares; um dos alunos ficaria encarregado. de conversar com os pais e o outro de anotar os diálogos.

Os alunos selecionariam os pais segundo o seu interesse. Eram aconselhados a utilizar a primeira oportunidade de contato apenas para observar os pais; conhecer, talvez, como determinado pai demonstra sua ansiedade e como ela é prejudicial à criança. Outra sugestão era descreverem o relacionamento entre pais e filhos, para conhecerem o grau de ajustamento entre eles e verificarem a capacidade dos pais de auxiliar os filhos quanto à adaptação ao meio hospitalar, aos tratamentos e a separação deles.

Quanto às características do modo de entrevistar os pais, estimulávamos os alunos a darem preferências à entrevista não diretiva. Os alunos se aproximariam dos pais com a preocupação primeira de ouvílos em suas histórias, de perceber em primeiro lugar o interesse dos pais, de identificar o seu foco de atenção e as causas de sua ansiedade. Os alunos deveriam demonstrar aceitação pelos pais, ouvindo suas perguntas. Discutíamos a importância de verificarem o significado das perguntas dos pais antes de respondê-las e de não se impressionarem no caso de precisarem se orientar com alguém da clínica. No caso das perguntas se referirem ao estado de saúde dos filhos, aconselhamos a devolverem estas perguntas, porque os pais têm suas próprias idéias e é melhor conversar com eles com base em suas percepçớes e em sua linguagem.

Quanto aos problemas colocados pelos pais, salientávamos a importância de, ao invés de dar soluçōes, o aluno deveria buscar as relaçðes entre causa e efeito dos problemas apresentados, incentivando e aproveitando a capacidade de raciocinar dos pais, também com base em suas percepçóes.

Finalmente, quanto à forma de aconselhar ou selecionar alternativas de soluçōes para problemas dos pais, discutimos com os alunos sobre os fatores que contribuiriam para que os pais pudessem melhor entender, aceitar e seguir a orientação. Em outras palavras analizávamos com os alunos a importância de identificarem e utilizarem as idéias, a motivação, os planos, as experiências e os recursos materiais dos pais, a fim de capacitá-los melhor para a assistência à criança hospitalizada. 


\section{REFERENCIAS BIBLIOGRAFICAS}

1. BRIGHT, F. The pediatric nurse and parental anxiety. Nurs. Forum. Hillsdale, 4 (2): $31-47$, May. 1965.

2. BRIGHT, F. Parental anxiety-a barrier to communication. In: AMERICAN NURSE'S ASSOCIÁTiON. Ana Clinical Sessions: 1966. New York, Appleton-Century-Crofts, 1966. p. 13-20.

3. COATES, V. et alii. Síndrome da criança batida. J. Pediat., Rio de Janeiro, 38 (9-10): 265-70, set/out. 1973.

4. ECKELLS, J.A. Home follow-up of mothers and their failure-to-thrive children, using planned nursing intervention. In: AMERICAN NURSE'S ASSOCIATION; Ana Clinical Sessions: 1968: New York, Appleton-Century-Crofts, 1968. p. 12-9.

5. FREIBERG, K.H. How parents react when their child is hospitalized, Amer. J. Nurs. New York, $72(7): 1270-2$, July, 1972.

6. FRIEDMAN, A.L. et alii. Nursing responsibility in child abuse. Nurs. Forum, Hillsdale, 15 (1):95.112, 1976.

7. HARRISON, L.L. Nursing intervention with the failure-to-thrive family, Matermal Child Nurs., New York, $I$ (2):111-6, Mar/Apr. 1976.

8. ISSNER, N. The family of the hospitalzed child. Nurs. Clin. N. Amer., Philadelphia, 7 (1): 5-12, Mar. 1972.

9. JERSILD, A.T. Psicologia da Criança. Belo Horizonte, Itatiaia, 1966. p. 143-86.

10. KORSH, B.M. Practical techniques of obserwing, interviewing and advising in practice as demonstrated in an attitude study project. Pediatrics, Springfield, 18:467-90, 1956.

11. MAHAFFY, P.R. Nurso-parent relationships in living - in situations. Mursing Forum, 3 (2): 53-68, 1964.

12. MAHAFFY, P.R. The effects of hospitalization on children admitted for Tonsillectomy and adenoidectomy. Nurs. Res., New York, 14 (1):12-9, Mar., 1965.

13. MARLOW, D.R. Textbook of pediatric nursing, 4, ed. Philadelphia, Saunders, 1973. p. $62-4$.

14. PORTER, C.P. Maladaptativa mothering patterns: nur sing intervention. In: AMERICAN NURSE'S ASSOCIATION. Ana Clinical Sessions: 1972. New York, Appleton-CenturyCrofts, 1972, p. 158-61.

15. RHEINGOLD, H.L. The measurement of maternal care. In: MEDINNUS, G.R. Reading in psychology of parent-child relations. New York, John Wiley \& Sons, 1967, p. 65-74.

16. ROY, C. Role cues for the mother of the hospitalizad child. In: AMERICAN NURSE'S AS. SOCIATION. Ana Clinical Sessions: 1968. New York, Appleton-Century-Crofts. 1968, p.199-206.

17. SCOFIELD, C. Parents in the hospital. Nurs. Clin. N. Amer., Philadelphia, $4: 59-67$, Mar. 1969. 